\title{
An old disease, a new disease or something in between: evidence from China
}

Youxin Wang, Tian Zhang and Wei Wang

In a recent Science and Society article by A. Rosalie David and Michael R. Zimmerman (Cancer: an old disease, a new disease or something in between? Nature Rev. Cancer 10, 728-733 (2010) $)^{1}$, the evidence of cancer in the literature and palaeopathological specimens primarily from ancient Egyptian and Greek societies, as well as the evidence of cancer in fossilized animals and early humans, was discussed. Based on this evidence the authors proposed that cancer was rare in antiquity. However, this conclusion might need further verification as they neglected the literature and evidence from China.

Cancer in ancient China was first documented in oracles, written in about the fourteenth to the eleventh centuries BCE. In Inner Canon of Yellow Emperor (475-221 вСE) $)^{2}$, the aetiology, pathology and symptoms of cancer were well documented, and it was proposed that tumorigenesis was associated with maladjustment, dietary factors, body deficiency and depression. The Classic of Mountains and Seas (before $221 \mathrm{BCE})^{3}$, recorded the medicines used for the treatment of cancer, such as seaweed and Thallus Laminariae, which is still used in China today. Documented in Jin Shu $(648 \mathrm{CE})^{4}$ is the first recorded exairesis (removal) of cancer.

It should be noted that infection with cancer-associated viral agents such as the Epstein-Barr virus and human papillomavirus, for example, might also lead to an increase in the proportion of cancer mortality in modern societies.

Youxin Wang and Wei Wang are at the School of Public Health and Family Medicine, Capital Medical University, Beijing 100069, China.

Wei Wang is also at the Graduate University, Chinease Academy of Sciences, Beijing 100049, China.

Tian Zhang is at the Editorial Office of China Biotechnology, National Science Library, Chinese Academy of Sciences, Beijing 100080, China.

Correspondence to Y.W. e-mail:wei6014@gucas.ac.cn doi: $10.1038 /$ nrc2914-c2

1. David, A. R. \& Zimmerman, M. R. Cancer: an old disease, a new disease or something in between? Nature Rev. Cancer. 10, 728-733 (2010).

2. Yao, C.P. (interpreter) Inner Canon of Yellow Emperor (Zhonghua Book Company, 2010).

3. Birrell, A. (interpreter) The Classic of Mountains and Seas (Penguin Classics, 2000)

4. Fang, X. L., Chu, S. L. \& Xu, J. Z. et al. Jin Shu (648)

Competing interests statement

The authors declare no competing financial interests. 